\title{
ASSESSMENT OF DESIGNED AND MEASURED MECHANISTIC PARAMETERS OF CONCRETE PAVEMENT FOUNDATION
}

\author{
YANG ZHANG ${ }^{1 *}$, PAVANA VENNAPUSA ${ }^{2}$, \\ DAVID JOSHUA WHITE ${ }^{3}$ \\ ${ }^{1,3}$ Dept of Civil, Construction and Environmental Engineering, \\ Iowa State University, Ames, Iowa USA \\ ${ }^{2}$ Ingios Geotechnics Inc., Little EIm, Texas, USA
}

Received 18 July 2018; accepted 10 January 2019

\begin{abstract}
There are plenty of in situ tests available to examine pavement foundation performance regarding stiffness and support conditions. This study evaluates several in situ tests of the stiffness and support conditions of concrete pavement foundation layers. The principal objective of this study was to evaluate the outputs from Dynamic Cone Penetrometer tests and Falling Weight Deflectometer tests. The California Bearing Ratio from Dynamic Cone Penetrometer tests and the deflection data from Falling Weight Deflectometer tests were correlated to the design parameter - modulus of subgrade reaction $k$ through correlations employed in pavement design manuals. Three methods for obtaining the $k$ values were conducted, with the intent to evaluate which method provides the results most similar to the target value and whether the studied correlations are reliable. The back-calculated $k$ values from Falling Weight Deflectometer deflections and the weak layer California Bearing Ratio correlated $k$ values based on the Portland Cement Association method were close to the target value, while the California Bearing Ratio empirically correlated $k$ based on the American Association of State Highway and Transportation Officials method presented values significantly higher than the target value. Those previously reported correlations were likely to overestimate the $k$ values based on subgrade California Bearing Ratio values.
\end{abstract}

Keywords: modulus of subgrade reaction, pavement design, pavement foundation, stiffness, support condition, Various Quality Control/Quality Assurance (QA/QC) test.

\footnotetext{
* Corresponding author. E-mail: alex19@iastate.edu 


\section{Introduction}

Various Quality Control (QC) and Quality Assurance (QA) test methods for monitoring the mechanical properties of pavement foundations have gained interest in transportation agencies. These QC/QA tests are typical stiffness- or strength-based approaches to evaluate the elastic modulus or bearing strength of foundation layers, for example, Falling Weight Deflectometer (FWD) test and Dynamic Cone Penetrometer (DCP) test (Konrad \& Lachance, 2001; Newcomb \& Birgisson, 1999). The modulus of subgrade reaction $(k)$ is a key parameter that is widely used from the $70 \mathrm{~s}$ by U.S. pavement engineers to design and characterise roadbed support conditions (Chen, Lin, Liau, \& Bilyeu, 2005; Darter, Hall, \& Kuo 1995; Li, Ashlock, Cetin, Jahren, \& Goetz, 2018; Thornton, 1983).

Although in situ, $k$ values are directly measureable through static plate load testing the measurements are time-consuming and expensive to set up (Vennapusa, Zhang, \& White, 2018). Therefore, other testing methods are frequently used by transportation agencies to derive $k$ values indirectly. Deflection tests using FWD are most popular because they are fast and labour saving (Puppala, 2008; Transportation Officials, 1993, 2008; Zhang, Vennapusa, White, \& Johnson, 2018). Additionally, the DCP test is another test approach, which has been recommended in the AASHTO (Transportation Officials, 2008) design guide as a method to determine California Bearing Ratio, which is often empirically correlated to $k$ value, and the DCP test device is much less expensive than other tests. While these tests are capable of determining various parameters other than $k$, highway agencies in the Unites States continue to rely on $k$ value for pavement designs, since this parameter has been employed in the most commonly used pavement design manuals for foundation design since the 70s, such as PCA (Packard, 1984) and AASHTO (Transportation Officials, 1993). Even though research has been performed to evaluate the relationships between a range of in situ QC/QA test measurements and the design parameter $k$, it is needed to verify further if the existing correlations that are usually adopted by pavement engineers are adequate for estimating $k$ for current practices.

In this study, DCP tests were conducted on the foundation layers to obtain the foundation layer stiffness. After the construction was completed, FWD tests were conducted on the pavement surface, where the DCP tests were previously conducted. The CBR calculated from DCP test results and the deflection data from FWD tests were correlated to the design parameter - modulus of subgrade reaction $k$ through correlations employed in pavement design manuals PCA (Packard, 1984) and AASHTO (Transportation Officials, 1993) and through a back-calculation method. Three methods for obtaining the $k$ values 
were conducted; with the intent to evaluate, which method provides the results most similar to the target value and whether the studied correlations are reliable. The relationships between the $k$ values back calculated from FWD measurements and the calculated CBR from DCP test results were compared to correlations reported in previous studies.
Assessment of Designed and Measured Mechanistic Parameters of Concrete Pavement Foundation

\section{Background}

\subsection{Project overview}

This project was located on U.S. Highway 30 in Boone County, Iowa and involved removal of the existing old pavement between mileposts 139.00 and 147.27. The existing pavement showed severe surface distresses with reflective cracking and vertical upheave near joints, especially during winter. Initial field investigations by the Iowa Dept of Transportation (DOT) rated the ride quality of the pavement section as "poor" based on Pavement Condition Index (PCI) ranging between 54 and 56 on a $0-100$ scale. The distresses observed on the existing pavement were the leading causes of the low PCI rate, which critically affect the serviceability, driving comfort and even safety. The existing pavement PCI was at the tail of the PCI versus service life sigmoidal curve, and the owner decided to reconstruct this pavement section.

As part of the reconstruction work, which began in the summer of 2011, the existing pavement and the asphalt treated base layers were removed, and the subgrade was undercut during the reconstruction process to place a nominal $410 \mathrm{~mm}$ (16 in) thick modified subbase over the existing natural subgrade. The modified subbase layer consisted of 150 mm (6 in) thick RPCC (Recycled Portland Cement Concrete) material at the surface underlain by $254 \mathrm{~mm}$ (10 in) thick mixture of RPCC-RAP

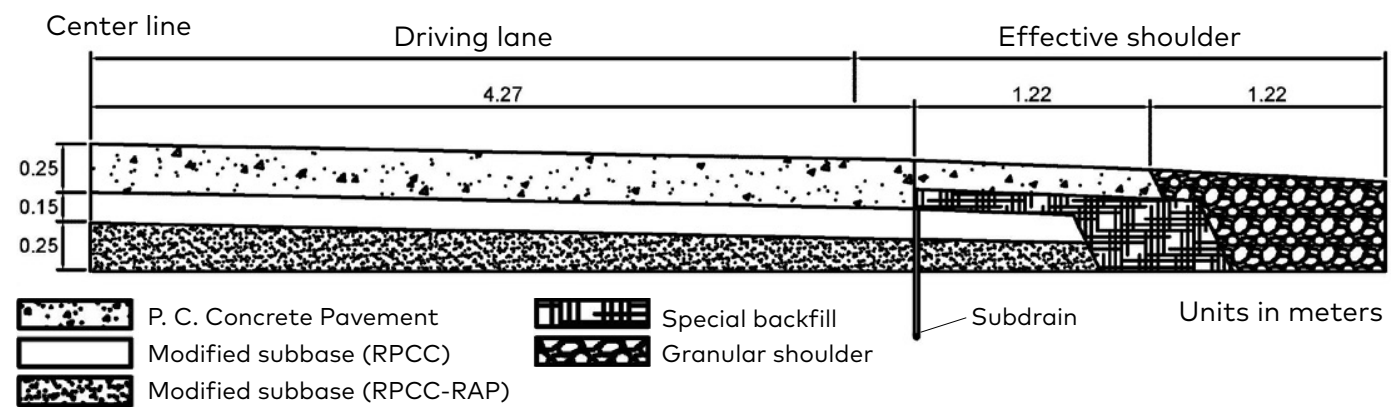

Figure 1. The reconstructed pavement and foundation layer cross-section of this project 
(Reclaimed Asphalt Pavement) material. A nominal $254 \mathrm{~mm}(10 \mathrm{in})$ thick Jointed Plain Concrete Pavement (JPCP) was placed on the reconstructed foundation layers. The Iowa DOT according to the PCA (Packard, 1984) method conducted thickness design of the reconstructed pavement, by targeting the modulus of subgrade reaction $(k)$ value at $41 \mathrm{kPa} / \mathrm{mm}(150$ pci) for the foundations. The reconstructed pavement and foundation layer cross-section is shown in Figure 1. Iowa DOT rated the ride quality of the pavement section as "good" based on PCI ranging between 95 and 100 after two years of service. As an essential indicator of the overall pavement condition regarding roughness, distress extent, deflection, and skid resistance, the reconstructed pavement presented a significantly higher PCI rate than the deteriorated pavements before reconstruction.

\subsection{Literature review}

Various thickness design procedures have been developed since the 1970s for concrete pavement design. PCA (Packard, 1984) and AASHTO (Transportation Officials, 1993) design procedures have been the most popularly used methods by state highway agencies in the United States, while there is increasing interest in implementing the mechanisticempirical design guide as AASHTO (Transportation Officials, 2008). While the AASHTO (Transportation Officials, 2008) procedure is a significant advancement over the PCA (Packard, 1984) and AASHTO (Transportation Officials, 1993) procedures regarding analysing the pavement responses, the key design parameter used to characterise foundation layer support is still the modulus of subgrade reaction $k$ value. Resilient modulus $M_{r}$ value is one of the design parameters in AASHTO (Transportation Officials, 2008), but the $M_{r}$ value needs to be converted to the $k$ value using empirical relationships in the design process. $C B R$ is another widely used value for QC/QA during or after construction. Some direct and indirect correlations between $C B R$ and $k$ have been commonly used. Studies have been conducted with the objective of comparing in situ or laboratory measurements to the design parameter values (Barker \& Alexander, 2012; Chen, Lin, Liau, \& Bilyeu, 2005; Darter, Hall, \& Kuo, 1995; Li, J., White, Stephenson, \& Li, C., 2019).

Chen, Lin, Liau, \& Bilyeu (2005) investigated the correlation between DCP measurements and moduli of pavement foundation layers. The layer moduli were determined by back-calculating FWD deflection measurements using a computer program "MODULUS", which adopted a linear-elastic analysis. The output DCP measurement was Penetration Rate (PR) with units of mm per blow (Dynamic Penetration Index (DPI) in this study). One hundred ninety-eight test locations on asphalt concrete pavements were selected to conduct both DCP and FWD tests. Test 
locations were with various granular subbase thickness and pavement Assessment of Designed conditions. A previous study also by Chen, Wang, \& Bilyeu (2001) reported that PR values changed as DCP was performed on pavement surface or directly on foundation layers, due to the loading from the surface layer. Modification coefficients were proposed in that study to transfer PR values between surface and foundation testing measurements, respectively, for subbase and subgrade. A correlation equation was presented in Chen, Lin, Liau, \& Bilyeu (2005) to estimate layer module based on PR for both subbase and subgrade. The equation developed in this study matched the conventional correlation, Powell model (Powell, Potter, Mayhew, \& Nunn, 1984). It was found that the difference between these two correlations varied as the PR changed. When the PR was smaller than $10 \mathrm{~mm} /$ blow, the difference was over $10 \%$, and it reduced to about $1.7 \%$ when the PR reached $80 \mathrm{~mm} /$ blow. The specific materials investigated in the studies by Powell, Potter, Mayhew, \& Nunn (1984) and Chen, Lin, Liau, \& Bilyeu (2005) possibly have led to different correlations.

Ping \& Sheng (2011) conducted a study investigating the correlation relationship between the $k$ and the $M_{r}$ of local pavement subgrade soils. The $k$ values in that study were obtained by conducting in situ static plate load tests directly on the subgrade layer. Two methods, laboratory triaxle testing and simulated cyclic plate load testing, were applied in the study to measure the soil $M_{r}$. Comparing test results based on strains measured at the middle half of the specimens; the $M_{r}$ measured from triaxle testing was close to the values measured from simulated testing. However, test results based on the specimen full strains indicated that the triaxle $M_{r}$ differed from the simulated $M_{r}$, and differences between these two values increased as the $M_{r}$ increased. Ping \& Sheng (2011) also reported the findings by correlating the laboratory triaxle $M_{r}$ and in situ static plate load $k$. The conversion equation from $M_{r}$ to $k$ was close to the AASHTO correlation relationship, which considered the subgrade linearly elastic, as the conversion factor was 2.25 in comparison with the AASHTO recommended value of 2.03 in the metric unit.

Barker \& Alexander (2012) reviewed the existing correlations for estimating $k$ and effective $k$ that considered the influence from subbase thickness. Several linear relationships between $k$ and $C B R$ were summarised in this study. The most critical uncertainty focused on the conversion factor between these two parameters. In general, this factor varied from 6.5 to 20 (transferring $C B R$ to $k$ ). Barker \& Alexander (2012) also provided a detailed procedure of theoretically calculating $k$ from $C B R$, which used Young's modulus, $E$ as a medium parameter. The result showed that 6.5 was the number theoretically to be used for the conversion. No later study has reported any number lower than 6.5. Barker \& Alexander (2012) then conducted plate load tests to measure 
the in-situ $k$ values directly and compared them to the $C B R$ values. Based on the results from that study and existing correlations, the values of the conversion factor were classified into two parts. Non-granular materials had a conversion factor approaching 20 , while the factor for granular materials approached the theoretical number of 6.5 .

\section{Test methods and data interpretation approach}

In this study, DCP tests were conducted on the foundation layers to obtain the foundation layer stiffness. After the construction was completed, FWD tests were conducted on the pavement surface at the centre of each slab, where the DCP tests were previously conducted.

\subsection{Dynamic cone penetrometer test}

Dynamic Cone Penetrometer tests were performed by ASTM D6951-03 Standard Test Method for Use of the Dynamic Cone Penetrometer in Shallow Pavement Applications to determine DPI in a unit of $\mathrm{mm} / \mathrm{blow}$ to calculate CBR using Eq. (1).

$$
C B R=\frac{292}{D P I^{1.12}},
$$

where $C B R$ is California Bearing Ratio and DPI is Dynamic Penetration Index.

Tests were conducted down to a depth of about $2 \mathrm{~m}$ below the pavement surface, by drilling a $20 \mathrm{~mm}$ hole in the pavement down to the top of the underlying base layer (Figure 2a). The DCP test results are presented as $C B R$ with depth profiles and as point values of $C B R_{\mathrm{SG}}$ representative of the subbase layer and $C B R_{\mathrm{SG}}$ representative of the top $305 \mathrm{~mm}$ of the subgrade. The top $305 \mathrm{~mm}$ of the subgrade was selected as the subgrade layer because it is typically the thickness used to scarify and compact the material during construction. The point data values represent the weighted average $C B R$ within each layer.

All DCP-CBR profiles were also reviewed to determine "weak" layers within the subgrade down to the bottom of the profile. An average $C B R$ of a minimum of $75.6 \mathrm{~mm}$ (3 in.) thick layer within the top $1.5 \mathrm{~m}$ of subgrade (represented as $C B R_{\text {SG-weak }}$ ) was calculated. The $C B R_{\text {SG-weak }}$ was determined to assess whether the weak layer influences the composite support conditions.

The $C B R_{\mathrm{SG}}$ and $C B R_{\mathrm{SG} \text {-weak }}$ values were converted to $M_{r \text {-SG }}$ and $M_{r \text {-SG-weak }}$ of subgrade, using nomographs provided in AASHTO (Transportation Officials, 1993). AASHTO (Transportation Officials, 1993) uses the 
following empirical relationship to convert $M_{r}$ to $k$ value (Eq. (2)), where $k$ is in a unit of $\mathrm{kPa} / \mathrm{mm}$ and $M_{r}$ is in a unit of $\mathrm{MPa}$ :

$$
k=2.3 M_{r}
$$

where $k$ is the modulus of subgrade reaction and $M_{r}$ is resilient modulus.

\subsection{Falling Weight Deflectometer test}

Falling Weight Deflectometer tests were conducted near mid-panel by ASTM D4694-09 Standard Test Method for Deflections with a FallingWeight-Type Impulse Load Device using a segmented $300 \mathrm{~mm}$ diameter loading plate by applying one seating drop and four loading drops (Figure 2b). The applied loads varied from $22 \mathrm{kN}$ to $75 \mathrm{kN}$. The peak
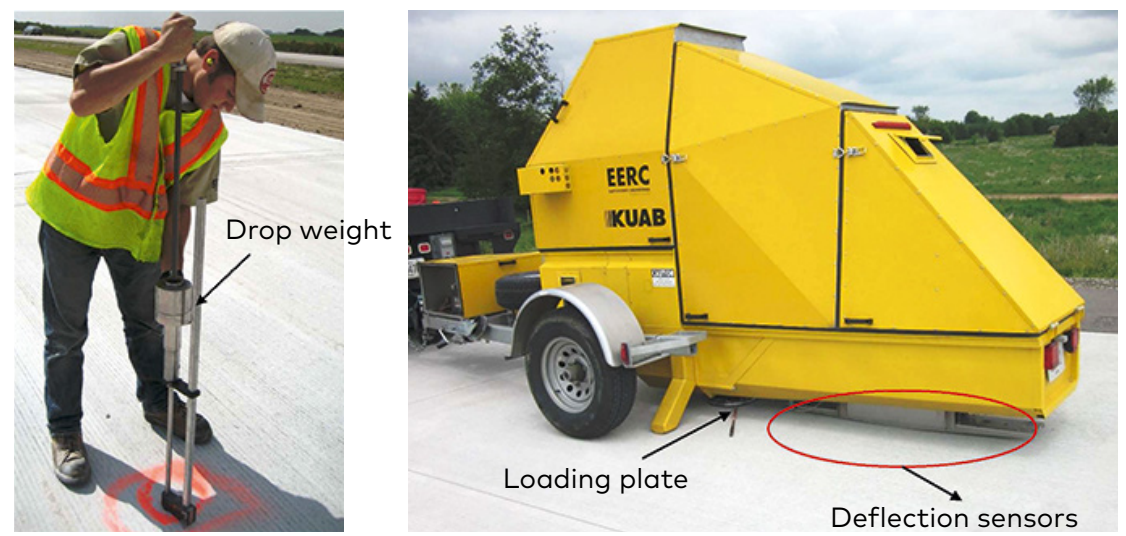

a) Dynamic Cone

b) Falling Weight Deflectometer
Assessment

of Designed and Measured

Mechanistic

Parameters

of Concrete

Pavement

Foundation

Penetrometer

Loading plate and deflection sensors setup (Plan View)

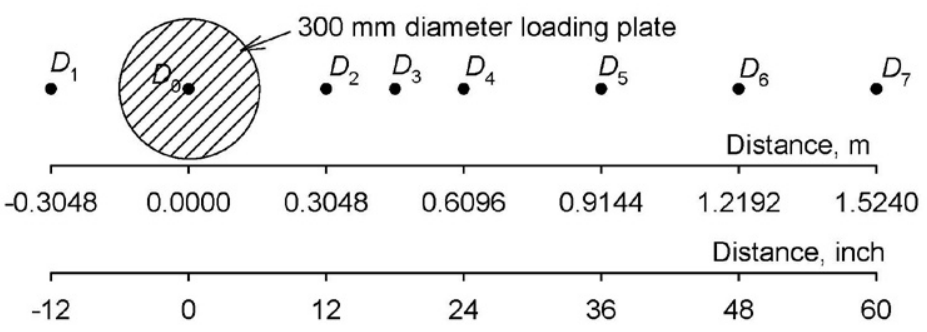

c) deflection sensor setup of Falling Weight Deflectometer

Figure 2. In situ testing equipment used in this study 
deflection values measured directly beneath the testing plate $\left(D_{0}\right)$ and at several locations away from the testing plate up to about $1.52 \mathrm{~m}$ away from the plate were normalised to $40 \mathrm{kN}$ (9000 lbs) (Figure 2c).

\subsection{Determination of $\mathrm{k}$ values}

Subgrade $k$ values were determined directly from field measurements using FWD testing, empirical relationships from DCP test measurements, and empirical relationships from laboratory measurements. All of these values are compared in this report concerning the design assumed value. The $k$ values determined using different procedures and the notations are listed below:

- $k_{\mathrm{PCA}(1984)}$ - determined from CBR using the correlation provided in PCA (Packard, 1984). A chart is provided in PCA (Packard, 1984) to estimate the modulus of subgrade reaction logarithmically based on $C B R$ values ranging from 2 to 100 .

- $k_{\text {AAshto(1993) }}$ - determined using Eq. (2), where $v$ is determined from $C B R_{\mathrm{SG}}$ or $C B R_{\mathrm{SG}-\text { weak }}$ using the correlation chart provided in AASHTO (Transportation Officials, 1993). California Bearing Ratio values ranging from 1 to 100 are used to estimate $M_{r}$ ranging from 2,000 psi to $40,000 \mathrm{psi}(13.79 \mathrm{MPa}$ to $27.58 \mathrm{MPa})$.

- $k_{\mathrm{FWD}-\text { static-corr }}$ - determined from the FWD test and corrected for slab size. The detailed procedures of the analysis are elaborated below.

The FWD deflection basin data were analysed to determine values using the Absolute, Relative, Exploration \& Exploitation and Analysis (AREA) method described in AASHTO (Transportation Officials, 1993). The AREA method was first proposed by Hoffman (1981) for flexible pavements and has since been applied extensively for concrete pavements (Darter, Hall, \& Kuo, 1995). Since the $k$ value determined from the FWD test represents a dynamic value, it is referred to here as $k_{\text {FWD-Dynamic. }}$ Deflections obtained from four sensors are used in the AREA calculation. AREA is calculated using Eq. (3) and has dimensions of length (inches), as it is normalised with deflections under the centre of the plate $\left(D_{0}\right)$ :

$$
A R E A=6+12\left(\frac{D_{2}}{D_{0}}\right)+12\left(\frac{D_{4}}{D_{0}}\right)+6\left(\frac{D_{5}}{D_{0}}\right),
$$

where $D_{0}$ - deflections measured directly under the plate, (mm, inches); $D_{2}$ - deflections measured at $305 \mathrm{~mm}$ (12 inches) away from the plate centre (inches); $D_{4}$ - deflections measured at $610 \mathrm{~mm}$ (24 inches) away from the plate centre (inches); and $D_{5}$ - deflections measured at $914 \mathrm{~mm}$ (36 inches) away from the plate centre (inches). 
$A R E A$ method is also calculated using different sensor configurations Assessment of Designed and setups, i.e., using deflection data from 3, 5, or 7 sensors and those methods are described in detail in the literature (Smith, Wade, Bruinsma, Chatti, Vandenbossche, Yu, ... \& Tayabji, 2007; Stubstad, Jiang, \& Lukanen, 2006,).

In the early research conducted using the $A R E A$ method, the ILLISLAB finite element program was used to compute a matrix of maximum deflections at the plate centre and the $A R E A$ values by varying the subgrade $k$, the modulus of the PCC layer, and the thickness of the slab. Measurements obtained from FWD tests were then compared to the ILLI-SLAB program results to determine the values through backcalculation. Later, in the 1990s to replace the back-calculation procedure, Barenberg \& Petros (1991) and Ioannides (1990) proposed a forward solution procedure based on Westergaard solution for loading on an infinite plate. This forward solution presented a unique relationship between $A R E A$ value (for a given load and sensor arrangement) and the dense liquid radius of relative stiffness $(L)$ in which the $k$ value characterised subgrade. The radius of $L$ was estimated using Eq. (4):

$$
L=\left[\frac{\ln \left(\frac{x_{1}-A R E A_{4}}{x_{2}}\right)}{x_{3}}\right]
$$

where $x_{1}=36 ; x_{2}=1812.279 ; x_{3}=-2.559 ; x_{4}=4.387$. It must be noted that the $x_{1}$ to $x_{4}$ values vary with the sensor arrangement and these values are only valid for the $A R E A_{4}$ sensor setup. Once the $L$ value is known, the $k_{\text {FWD-Dynamic }}$ value was estimated using Eq. (5):

$$
k_{\mathrm{FWD}-\text { Dynamic }}=\frac{P D_{0}^{*}}{D_{0} L^{2}},
$$

where $P$ - applied load, lb; $D_{0}$ - deflection measured at plate centre, inches; $D_{0}{ }^{*}$ - non-dimensional deflection coefficient calculated using Eq. (6):

$$
D_{0}^{*}=a e^{-b e^{-c L}},
$$

where $a=0.12450 ; b=0.14707 ; c=0.07565$. It must be noted that these Eqs and coefficients are valid for an FWD setup with a $230 \mathrm{~mm}$ (11.81 in.) diameter plate.

The AREA method assumes the slab and the subgrade are horizontally infinite. This assumption leads to an underestimation of the $k$ value. Crovetti (1994) developed the following slab size corrections (Eqs (7) and (8)) for a square slab based on finite element analysis conducted using the ILLI-SLAB program, for use in the $k_{\text {FWD-Dynamic: }}$ :

$$
\text { Adjusted } D_{0}=D_{0}\left(1-1.15085 e^{-0.71878\left(\frac{L^{\prime}}{L}\right)^{0.80151}}\right) \text {; }
$$




$$
\text { Adjusted } L=L\left(1-0.89434 e^{-0.61662\left(\frac{L^{\prime}}{L}\right)^{1.04881}}\right),
$$

where $L^{\prime}$ - slab size (smaller dimension of a rectangular slab, length or width).

This procedure also has limitations:

1) it considers only a single slab with zero load transfer to adjacent slabs, and

2) it assumes a square slab.

The square lab assumption is considered to produce sufficiently accurate results when the smaller dimension of a rectangular slab is assumed as $L^{\prime}$ (Darter, Hall, \& Kuo, 1995). There are no established procedures reported to date on correcting for load transfer to adjacent slabs, which remains as a limitation of this method. In this project, $k_{\text {FWD-Dynamic }}$ values corrected for slab size are reported as $k_{\text {FWD-Dynamic-corr }}$.

AASHTO (Transportation Officials, 1993) suggests dividing the $k_{\text {FWD-Dynamic }}$ value by a factor of 2 to determine the equivalent $k_{\text {FWD-Static }}$ Value. For the analysis conducted in this research project, the $k_{\text {FWD-Dynamic-corr }}$ values are divided by 2 and are reported as $k_{\mathrm{FWD}-\text {-Static-corr }}$ values.

\section{Test results and analysis}

\subsection{In situ stiffness and strength tests}

Dynamic Cone Penetrometer tests were conducted at 20 test locations, with 10 locations each in the left and right lanes over a $100 \mathrm{~m}$ distance along the centre lane. The DCP-CBR and cumulative blows (i.e., total blows recorded to reach a specific penetration) with depth profiles for left and right lanes are presented in Figure 3. California Bearing Ratio values of each layer at each test location are plotted with distance in Figure 4. California Bearing Ratio values were lower in the top $150 \mathrm{~mm}$ of RPCC modified subbase layer than that in the bottom $250 \mathrm{~mm}$ of RPCC-RAP modified subbase layer. The average $C B R$ of the RPCC modified subbase layer was about 11, and the average $C B R$ of the RPCC-RAP layer was about 69 , though the laboratory tests showed $70 \%$ higher $C B R$ values of RPCC than RPCC-RAP. The subgrade was significantly variable in, and the average value for the top $300 \mathrm{~mm}$ was about 14 . The $C B R_{\text {SG-weak }}$ was about 7 , which represented the average value for a minimum of $75.6 \mathrm{~mm}$ ( 3 in.) thick "weak" layer within the top $1.5 \mathrm{~m}$ of the subgrade. Figure 3 was used to determine the weak layer in subgrade where has the lowest $C B R$, which is defined in Section 2.1. Moreover, values shown in Figure 4 were the ones used 
for further analysis on correlating the corresponding $k$ values at each test location.

Falling Weight Deflectometer tests were conducted on the pavement surface after construction. Tests were conducted near the mid-panel for $D_{0}$ and $I$ and at joints for $D_{0}, I$, and Load Transfer Efficiency LTE (Figure 5).
Assessment of Designed and Measured Mechanistic Parameters of Concrete Pavement Foundation

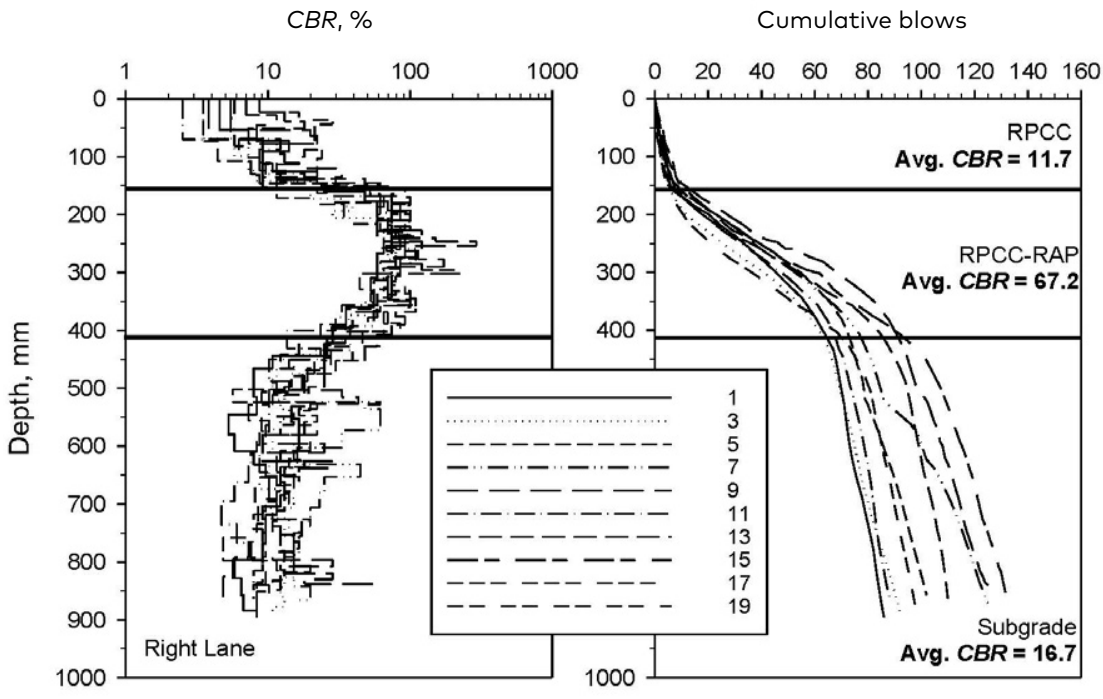

a) right lane

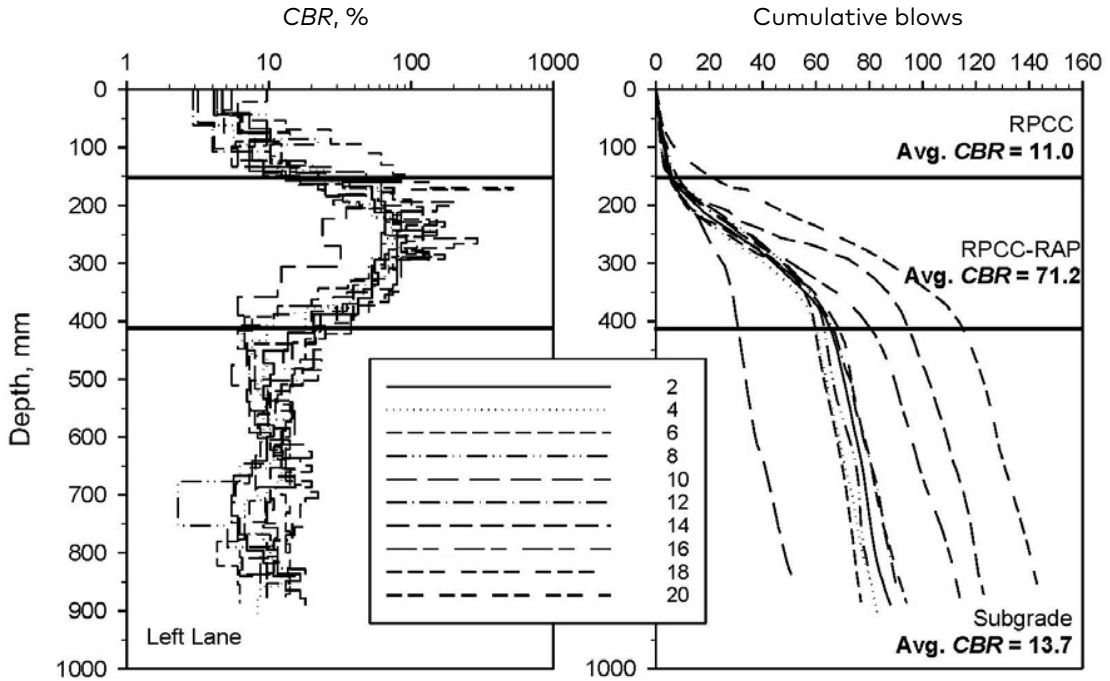

b) left lane.

Figure 3. Dynamic Cone Penetrometer-California Bearing Ratio and cumulative blows with depth profiles 


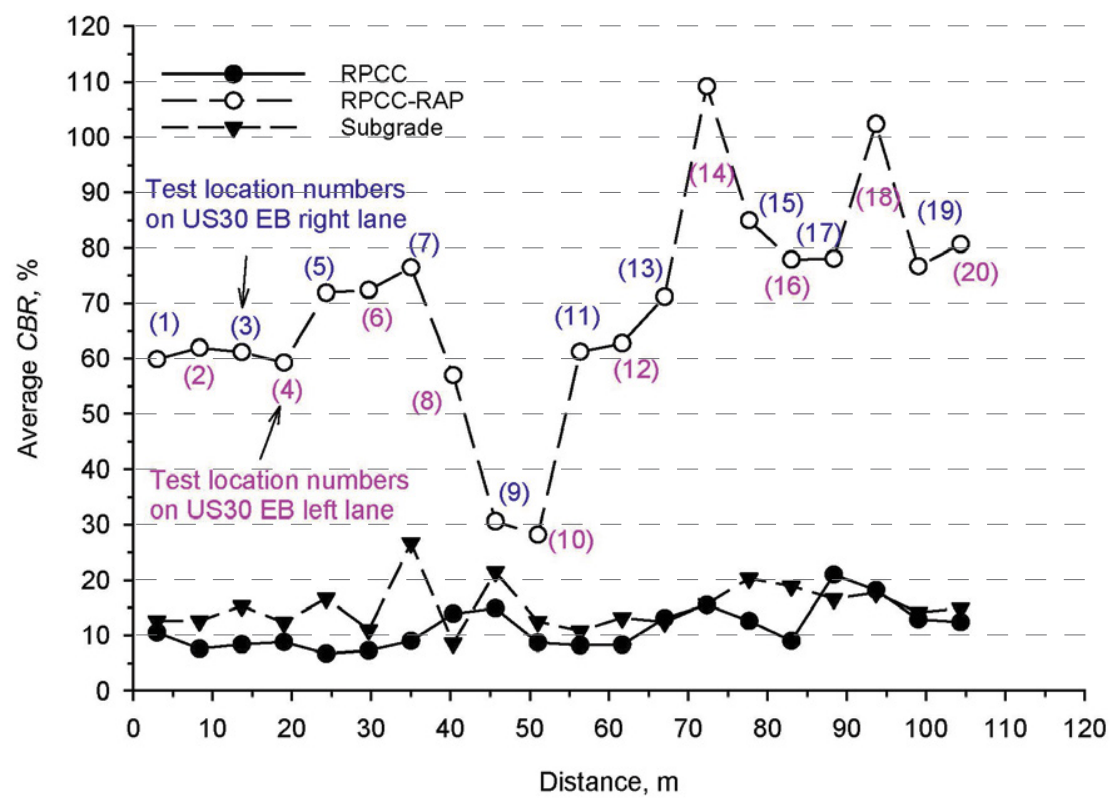

Figure 4. Layer California Bearing Ratio values at each test location

The $D_{0}$ varied slightly but presented significant differences between the measurements at mid-panel and joints. It ranged from 0.07 to $0.08 \mathrm{~mm}$ at mid-panel and $0.09 \mathrm{~mm}$ to $0.11 \mathrm{~mm}$ at joints. By the DCP results (refer to Figure 4), several of the test locations with lower $C B R$ values in subgrade displayed relatively higher deflections. Deflection data from other FWD sensors were used along with the corresponding $D_{0}$ measurements to calculate the $k$ values.

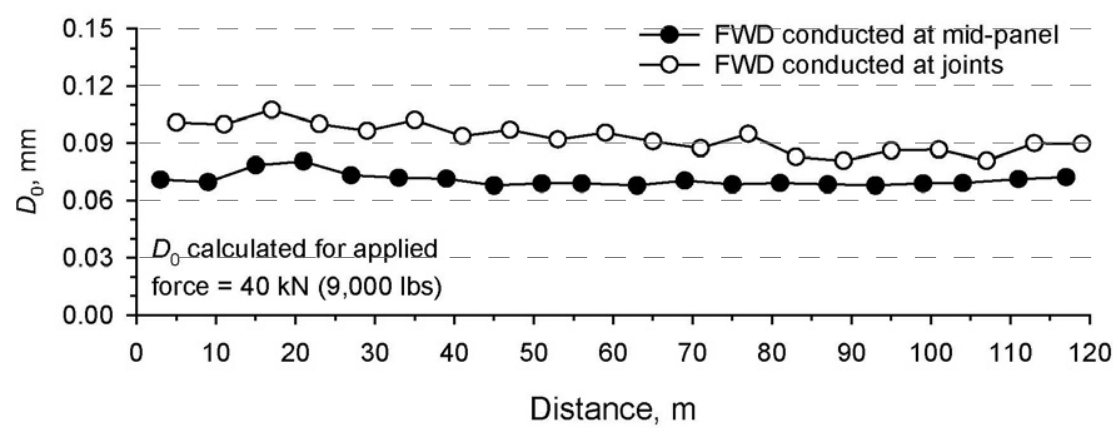

Figure 5. Falling Weight Deflectometer deflection results versus distance 


\subsection{Comparison of values with target design values}

The values along with distance estimated from FWD test data, and using the PCA and AASHTO correlations are plotted in Figure 6. Both $C B R_{S G}$ and $C B R_{\text {SG-weak }}$ were used in calculating the $k$ values with the AASHTO (Transportation Officials, 1993) and PCA (Packard, 1984) procedures. The average $k_{\text {FWD-Static-corr }}$ was about $37.1 \mathrm{kPa} / \mathrm{mm}$ with relatively small variety (7\% COV, COV is coefficient of variance), while $k_{\mathrm{AASHTO}(1993)}$ (Transportation Officials, 1993) showed a large variety between $40 \mathrm{kPa}$ to $160 \mathrm{kPa}$ based on $C B R_{\text {SG-weak }}$ and $120 \mathrm{kPa}$ to $260 \mathrm{kPa}$ based on $C B R_{\mathrm{SG}}$.

The average $k$ values determined from the three procedures are also presented as bar charts in Figure 7. The results showed that the

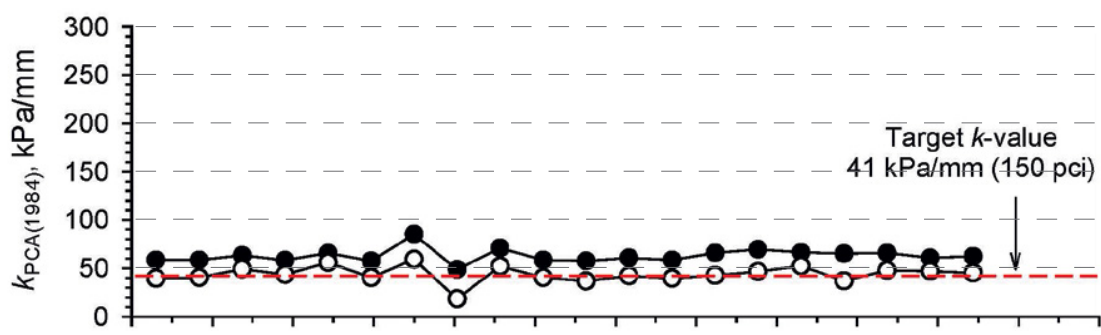

a) $k_{\mathrm{PCA}(1984)}$

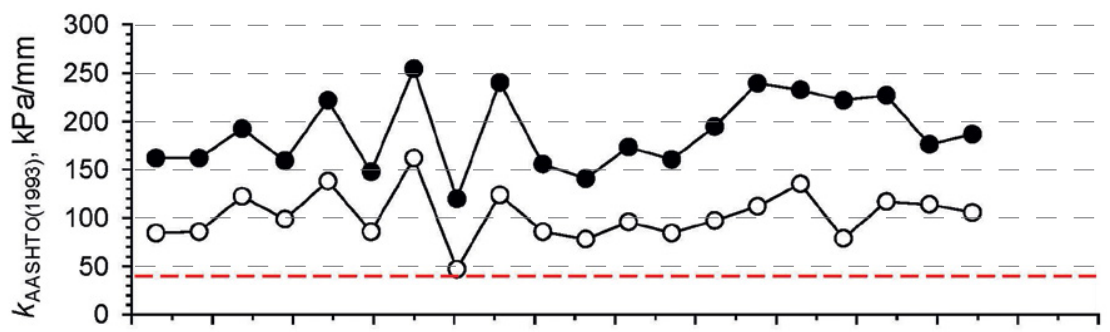

b) $k_{\text {AASHTO(1993) }}$

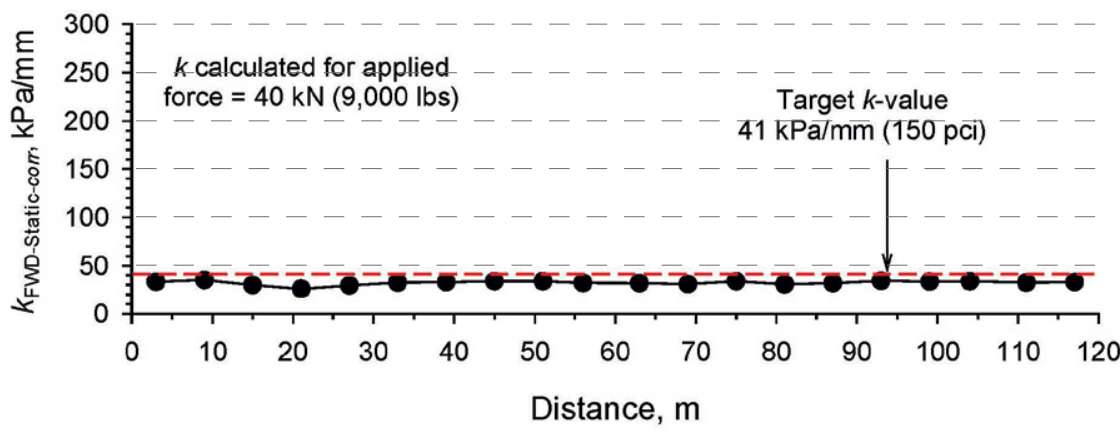

c) $k_{\text {FWD-Static-corr }}$

- based on $C B R_{\mathrm{SG}}$
- based on $C B R_{\mathrm{SG} \text {-weak }}$

Figure 6. Estimated $k$ values based on different methods 


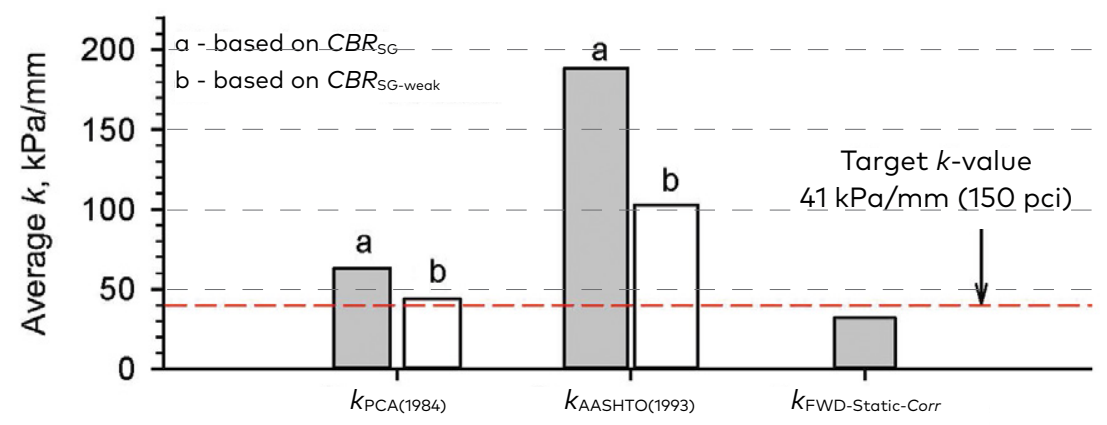

Figure 7. Bar chart comparing the design target $k$ value with measured and estimated $k$ values from field measurements

$k$ values determined from the FWD tests showed the lowest values, and were closer to the target design $k$ value, which is $41 \mathrm{kPa} / \mathrm{mm}$. On average, the average $k_{\mathrm{FWD}-\text {-Static-corr }}$ value was about 0.95 times the target $k$ value. The $k_{\mathrm{PCA}(1984)}$ calculated based on $C B R_{\text {SG-weak }}$ were also closer to the target $k$ value. The average $k_{\mathrm{PCA}(1984)}$ (Packard, 1984) calculated based on $C B R_{\mathrm{SG}}$ was about 1.4 times higher than the design $k$ value, which indicates a slight overestimation. The results based on the PCA correlations revealed that the weakest layer in the subgrade probably dominates the actual $k$ value of a concrete pavement foundation. In practice, the weakest layer $C B R$ are preferred to be used instead of the average $C B R$ to estimate $k$ and consequently evaluate the foundation performance.

In general, the $k$ values calculated using the empirical relationships between CBR and $k$ from AASHTO (Transportation Officials, 1993) produced the highest values. The average $k_{\text {AAshто(1993) }}$ (Transportation Officials, 1993) was about from two to four times higher than the design $k$ value. This finding indicated that the correlations specified in AASTHO (Transportation Officials, 1993) are likely to overestimate the $k$ values based on either the average subgrade $C B R$ or the weak layer $C B R$. This higher uncertainty in $k$ estimation possibly attribute to two factors. First, unlike the FWD deflection data back calculation, the AASHTO method is purely empirical. Second, unlike the PCA correlation method, which is a single step correlation, the AASHTO method requires two steps of correlations, which are converting CBR to $M_{r}$ and then $M_{r}$ to $k$. The AASHTO method is considered inadequate to be employed in the concrete pavement foundation quality control accounting for this finding. In comparison, the FWD back calculated $k$ values, and the PCA correlated $k$ values were more believable than the AASHTO correlated $k$. Therefore, in summary, if a pavement engineer needs to estimate the $k$ 
value, using the FWD back-calculation method as discussed or the PCA Assessment of Designed correlation is recommended.

Darter, Hall, \& Kuo (1995) reported data from long-term pavement performance (LTPP) test sections comparing subgrade CBR values and static $k_{\text {FWD-Static }}$ values as well as values from static plate load tests (Figure 8). Based on these data, they suggested an upper bound, a lower bound, and a midrange in estimating $k$ from $C B R$. Other data published by U.S. Army Corps of Engineers (Barker \& Alexander, 2012) and Thornton (1983) were added to this database in Figure 8 along with relationships suggested by Carlos Gonzalez from U.S. Army Corps of Engineers as presented in Barker \& Alexander (2012), and Packard (1973). It is unknown how the values are determined in the LTPP database and the U.S. Army Corps of Engineers studies. In Thornton (Thornton, 1983) study, was determined on laboratory samples compacted to similar field moisture and densities as under static PLTs conducted using a 30 in. diameter plate. Results from the U.S. Army Corps of Engineers were mostly below the midrange, and some were below the low range specified in Darter, Hall, \& Kuo (1995). Thornton (Thornton, 1983) data points were mostly within the lower and upper range bounds specified in Darter, Hall, \& Kuo (1995). However, all of these empirical correlations were explicitly linked to the material evaluated. Results obtained from this study were compared to this database. The effect of differences among local materials investigated was expected to result in discrepancies between the results of this study and the other studies.

With intent to evaluate the data from this study and a few other related studies, relationships and data published in the literature were plotted with the $k_{\text {FWD-Static-corr }}$ and $C B R_{S G}$ values in Figure $8 \mathrm{a}$ and with $C B R_{\text {SG-weak }}$ values in Figure $8(\mathrm{~b})$. The $C B R_{\text {SG-weak }}$ values obtained from this study were in line with published relationships for estimating $k$ values when the $C B R$ values are lower than 10 , but all the $C B R_{\mathrm{SG}}$ values were barely in line. Nevertheless, $C B R$ versus $k$ relationships displayed significant scatter and presented significant uncertainty in the correlations. The authors estimated the upper and lower bounds and mid-range based on the publisher relationships from five kinds of literature or design manuals. Data published in the literature fell into the area below the mid-range except for several data points from Darter, Hall, \& Kuo (1995). Corresponding to $C B R_{\mathrm{SG}}$, data from White \& Vennapusa (2014), and a project all fell significantly below the lower bound. The $C B R_{\mathrm{SG} \text {-weak }}$ data points primarily fell near the lower bound when the $C B R$ value was less than 20. A conclusion is drawn based on these findings is that almost all the relationships reported before are likely to overestimate the $k$ values based on subgrade $C B R$ values. The 


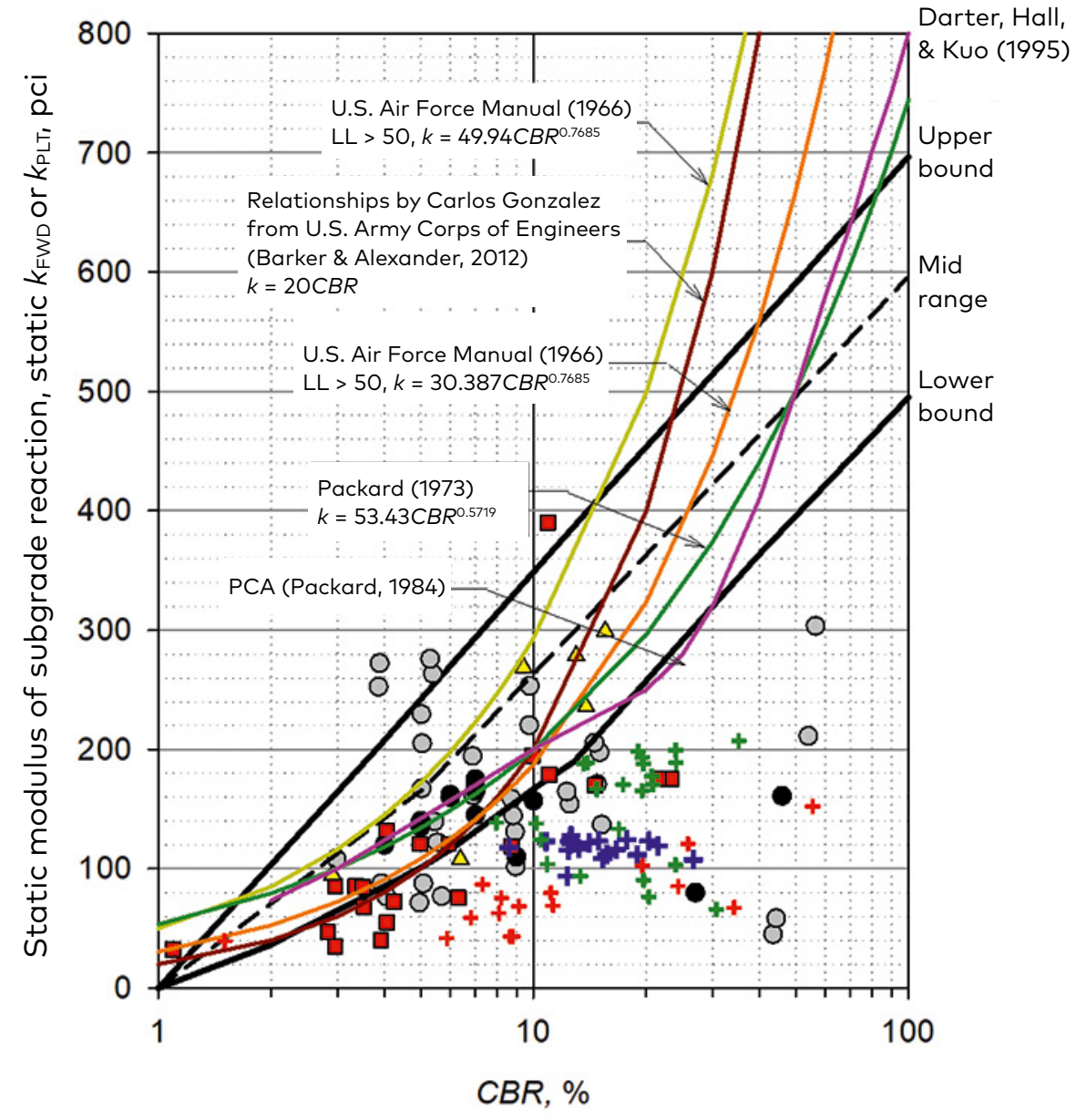

LTTP database - $k_{\text {FWD-Static-corr }}$ (Darter, Hall, \& Kuo, 1995)

- LTTP database - $k_{\mathrm{PLT}}$ (Darter, Hall, \& Kuo, 1995)

$\square$ U.S. Army Corps of Engineers - $k_{\mathrm{PLT}}$ (Barker \& Alexander, 2012)

$\triangle$ Lab CBR versus field $k_{\mathrm{PLT}}$ (Thornton, 1983)

+ This Project - $k_{\text {FWD-Static-corr }}$ versus CBR SG-weak

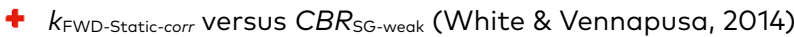

$+k_{\text {FWD-Static-corr }}$ versus CBR $R_{\mathrm{SG}-\text { weak }}$ (White, Vennapusa, Zhang, \& Johnson, 2016)

LL - Liquid Limit

a) average $C B R_{S G}$ 


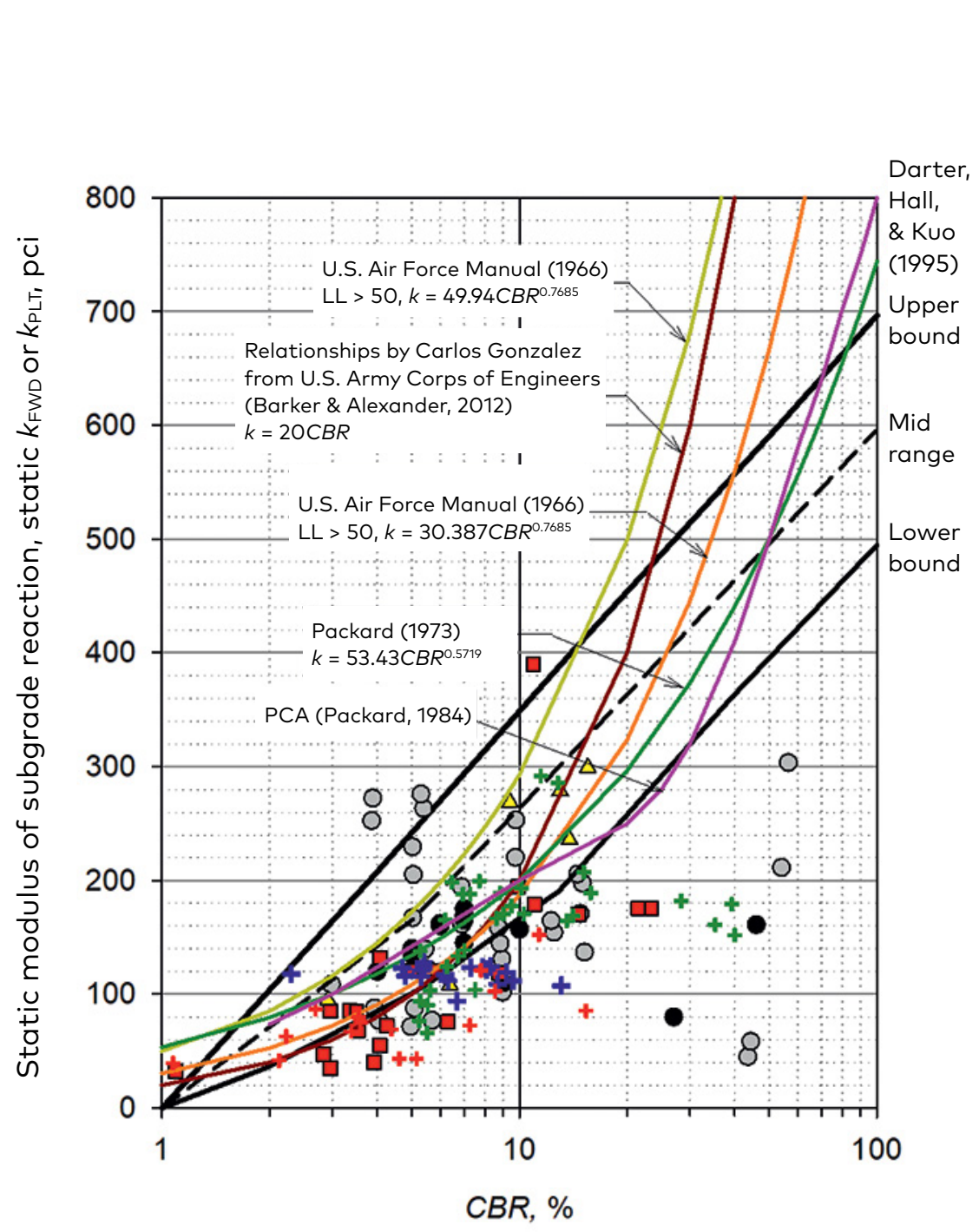

Yang Zhang,

Pavana Vennapusa,

David Joshua

White

Assessment

of Designed

and Measured

Mechanistic

Parameters

of Concrete

Pavement

Foundation

O LTTP database - $k_{\text {FWD-Static-corr }}$ (Darter, Hall, \& Kuo, 1995)

- LTTP database - $k_{\text {PLT }}$ (Darter, Hall, \& Kuo, 1995)

$\square$ U.S. Army Corps of Engineers - $k_{\text {PLT }}$ (Barker \& Alexander, 2012)

$\triangle$ Lab CBR versus field $k_{\text {PLT }}$ (Thornton, 1983)

+ This Project - $k_{\text {FWD-Static-corr versus } C B R_{\mathrm{SG} \text {-weak }}}$

$+k_{\text {FWD-Static-corr versus CBR }}$ SG-weak (White \& Vennapusa, 2014)

+ $k_{\text {FWD-Static-corr versus CBR }}$ SG-weak (White, Vennapusa, Zhang, \& Johnson, 2016)

LL - Liquid Limit

b) average $C B R_{\text {sG-weak }}$

Figure 8. Average $k_{\text {FWD-Static-corr }}$ versus average CBR values compared to relationships published in the literature 
weakest subgrade layer with the lowest $C B R$ value probably dominates the composite support condition of the subgrade.

Given that most test measurements showed back calculated $k$ values below the design values, it was unclear what level of support or $k$ value ought to be considered adequate in a design perspective. Based on the empirical nature of the process involved in determining $k$ value from the AREA method and the limited empirical evidence in correcting dynamic versus static values, it is important to note that the back-calculated $k$ values should be considered approximate and may not be appropriate for use directly in design. Field studies have shown empirical evidence that the FWD back calculated $k$ value is strongly related to the weakest layer properties in the top $1.5 \mathrm{~m}$ of the pavement foundation layer. Further, the direct measurement of $k$ values per AASHTO (FDOT, 2000) is recommended for comparison with design assumptions. With the advent of new technologies (e.g., automated plate load testing), it is now possible to obtain these measurements relatively quickly.

\section{Conclusions}

This study presented results from Dynamic Cone Penetrometer and Falling Weight Deflectometer tests used to evaluate the stiffness and support conditions of concrete pavement foundations. Output parameter values from this study were converted to the design parameter, modulus of subgrade reaction $k$ through three possible correlation approaches. The correlation methods used in this study were evaluated. The key conclusions drawn from this study are summarised as below.

1. The $k$ values back-calculated from the deflection data showed the lowest values rather than other correlated $k$ values. Moreover, these $k$ values were slightly lower than the target value used in the pavement design.

2. The $k$ values correlated through the Portland Cement Association relationships based on the weak layer California Bearing Ratio were most similar to the target design $k$ value. However, the $k$ values correlated using the same method but based on the average subgrade California Bearing Ratio presented slightly higher values than the target number.

3. The $k$ estimated through the American Association of State Highway and Transportation Officials empirical correlations produced the highest values, and they differed the most to the target design $k$ value. In general, the $k$ values were overestimated as two to four times higher than the target value with a wide 
variation. This correlation method provided the most substantial

Assessment of Designed uncertainty for estimation.

4. Those previously reported correlations were likely to overestimate the $k$ values from subgrade California Bearing Ratio. The back-calculated $k$ values based on deflection data should be considered approximate and may not be appropriate for use and Measured

Mechanistic

Parameters

of Concrete

Pavement

Foundation

\section{Acknowledgements}

This research was conducted under FHWA DTFH61-06-H-00011 Work Plan 18 and the FHWA Pooled Fund Study TPF-5(183). The authors would like to express their gratitude to the National CP Tech Centre, the FHWA, the Iowa DOT, and the other pooled fund states. Special thanks are given to Prof Robert Horton.

\section{REFERENCES}

Air Force Manual (1966). Airfield Rigid Pavement Evaluation - Air Force: Emergency Construction, TM 5-888-9, U.S. Army Corps of Engineers.

ASTM D4694-09 Standard Test Method for Deflections with a Falling-Weight-Type Impulse Load Device

ASTM D6951-03 Standard Test Method for Use of the Dynamic Cone Penetrometer in Shallow Pavement Applications

Barenberg, E. J., \& Petros, K. A. (1991). Evaluation of Concrete Pavements Using NDT Results. Final Summary Report (No. FHWA/IL/UI 233).

Barker, W. R., \& Alexander, D. R. (2012). Determining the Effective Modulus of Subgrade Reaction for Design of Rigid Airfield Pavements Having Base Layers. US Army Corps of Engineers, Engineer Research and Development Center, Geotechnical and Structures Laboratory.

Chen, D. H., Lin, D. F., Liau, P. H., \& Bilyeu, J. (2005). A correlation between dynamic cone penetrometer values and pavement layer moduli. Geotechnical Testing Journal, 28(1), 42-49. https://doi.org/10.1520/GTJ12312

Chen, D. H., Wang, J. N., \& Bilyeu, J. (2001). Application of dynamic cone penetrometer in evaluation of base and subgrade layers. Transportation Research Record: Journal of the Transportation Research Board, (1764), 1-10. https://doi.org/10.3141/1764-01

Crovetti, J. A. (1994). Design and evaluation of jointed concrete pavement systems incorporating free-draining base layers (Doctoral dissertation, University of Illinois at Urbana-Champaign).

Darter, M. I., Hall, K. T., \& Kuo, C. M. (1995). Support under Portland cement concrete pavements (No. Project 1-30 FY'93). 
Florida Dept of Transportation (FDOT). (2000). Florida Method of Test for Nonrepetitive Static Plate Load Test of Soils And Flexible Pavement Components. T-222. American Association of State Highway and Transportation Officials. Designation: FM 5-527. 2000.

Hoffman, M. S. (1981). Mechanistic Interpretation of Nondestructive Pavement Testing Deflections.

Ioannides, A. M. (1990). Dimensional analysis in NDT rigid pavement evaluation. Journal of Transportation Engineering, 116(1), 23-36. https://doi.org/10.1061/(ASCE)0733-947X(1990)116:1(23)

Konrad, J. M., \& Lachance, D. (2001). Use of in situ penetration tests in pavement evaluation. Canadian geotechnical journal, 38(5), 924-935. https://doi.org/10.1139/t01-024

Li, C., Ashlock, J. C., Cetin, B., Jahren, C. T., \& Goetz, V. (2018). Performance-Based Design Method for Gradation and Plasticity of Granular Road Surface Materials. Transportation Research Record, 0361198118787372. https://doi.org/10.1177\%2F0361198118787372

Li, J., White, D. J., Stephenson, W. R., \& Li, C. (2019). Considerations for laboratory resilient modulus testing of unbound pavement base materials. Construction and Building Materials, 195, 515-523.

https://doi.org/10.1016/j.conbuildmat.2018.11.049

Newcomb, D. E., \& Birgisson, B. (1999). Measuring in situ mechanical properties of pavement subgrade soils (Vol. 278). Transportation Research Board.

Packard, R. G. (1973). Design of concrete airport pavement (No. EB050. 03P).

Packard, R. G. (1984). Thickness design for concrete highway and street pavements.

Ping, W., \& Sheng, B. (2011). Developing correlation relationship between modulus of subgrade reaction and resilient modulus for Florida subgrade soils. Transportation Research Record: Journal of the Transportation Research Board, (2232), 95-107. https://doi.org/10.3141/2232-10

Powell, W. D., Potter, J. F., Mayhew, H. C., \& Nunn, M. E. (1984). The structural design of bituminous roads (No. LR 1132 Monograph).

Puppala, A. J. (2008). Estimating stiffness of subgrade and unbound materials for pavement design (Vol. 382). Transportation Research Board.

Smith, K. D., Wade, M. J., Bruinsma, J. E., Chatti, K., Vandenbossche, J. M., Yu, H. T., ... \& Tayabji, S. D. (2007). Using falling weight deflectometer data with mechanistic-empirical design and analysis. Draft Interim Report for FHWA DTFH61-06-C-00046, Applied Pavement Technology. Inc., Urbana.

Stubstad, R. N., Jiang, Y. S., \& Lukanen, E. O. (2006). Guidelines for review and evaluation of backcalculation results (No. FHWA-HRT-05-152). United States. Federal Highway Administration.

Thornton, S. I. (1983). Correlation of Subgrade Reaction with CBR, Hveem Stabilometer, or Resilient Modulus.

Transportation Officials. (1993). AASHTO guide for design of pavement structures, 1993 (Vol. 1). AASHTO.

Transportation Officials. (2008). Mechanistic-empirical pavement design guide: A manual of practice. AASHTO. 
Vennapusa, P. K., Zhang, Y., \& White, D. J. (2018). Assessment of Support

Assessment Conditions of Concrete Pavement Using FWD Deflection Basin Data. Journal of Testing and Evaluation, 47(4). https://doi.org/10.1520/jte20170226

of Designed and Measured Mechanistic

White, D. J., \& Vennapusa, P. (2014). Optimizing pavement base, subbase, and subgrade layers for cost and performance of local roads.

White, D. J., Vennapusa, P. K.R., Zhang, Y., \& Johnson, A. (2016). Assessment of Seasonal Variations in Concrete Pavement Foundation Layers - Multiple Parameters of Concrete Pavement Test Sections in Iowa. InTrans Project 09-352 Report. Iowa State University. Ames, IA.

Zhang, Y., Vennapusa, P. K., White, D. J., \& Johnson, A. E. (2018). Seasonal variations and in situ assessment of concrete pavement foundation mechanistic properties. International Journal of Pavement Research and Technology, 11(4), 363-373. https://doi.org/10.1016/j.ijprt.2017.09.007 